\title{
Aqueous and Vitreous Penetration of Linezolid and Levofloxacin After Oral Administration
}

\author{
Jomy M. George, ${ }^{1}$ Richard Fiscella, ${ }^{2}$ Michael Blair, ${ }^{3}$ Keith Rodvold, ${ }^{2}$ Lawrence Ulanski, ${ }^{3}$ \\ John Stokes, ${ }^{4}$ Norman Blair, ${ }^{3}$ and Laura Pontiggia ${ }^{5}$
}

\begin{abstract}
Purpose: To evaluate the time course of drug concentrations achieved in aqueous (AQ), vitreous (V), and serum (S) compartments after oral administration of linezolid and levofloxacin.

Design: Randomized, clinical trial.

Methods: Settings: Clinical practice. Patient population: Sixteen patients (16 eyes) undergoing vitrectomy who had not had a prior pars plana vitrectomy in the study eye were randomly assigned to one of 4 groups. Intervention: $\mathrm{AQ}, \mathrm{V}$, and $\mathrm{S}$ samples were obtained from all subjects after single concomitant doses of linezolid $600 \mathrm{mg}$ and levofloxacin $750 \mathrm{mg}$ between 1 and $12 \mathrm{~h}$ before the procedure: group $\mathrm{A}=1-3 \mathrm{~h}$; group $\mathrm{B}=3-6 \mathrm{~h}$; group $\mathrm{C}=6-9 \mathrm{~h}$; group $\mathrm{D}=9-12 \mathrm{~h}$. Main outcome measures: $\mathrm{AQ}, \mathrm{V}$, and $\mathrm{S}$ concentrations of linezolid and levofloxacin.

Results: Overall mean concentrations \pm standard deviation $(\mu \mathrm{g} / \mathrm{mL})$ achieved by linezolid in $\mathrm{AQ}, \mathrm{V}$, and $\mathrm{S}$ compartments were $3.32 \pm 2.06,2.98 \pm 1.87$, and $7.91 \pm 3.94$, respectively. Overall mean concentrations \pm standard deviation $(\mu \mathrm{g} / \mathrm{mL})$ achieved by levofloxacin in $\mathrm{AQ}, \mathrm{V}$, and $\mathrm{S}$ compartments were $2.19 \pm 1.92$, $1.95 \pm 1.27$, and $7.38 \pm 3.47$, respectively.

Conclusions: Single concomitant doses of linezolid and levofloxacin achieved AQ and V concentrations above the minimum inhibitory concentration for $90 \%$ of common ocular gram-positive and gram-negative pathogens up to $12 \mathrm{~h}$ after administration. The combination of linezolid and levofloxacin represents a viable option for the prophylaxis and management of endophthalmitis.
\end{abstract}

\section{Introduction}

D ELAY IN THE TREATMENT of bacterial endophthalmitis can lead to irreversible vision loss and is considered to be a medical emergency. ${ }^{1}$ Not only does time to therapy play an important role in successful therapy outcomes, but also the concentration-time profile at the site of infection has been correlated to outcomes as well. ${ }^{2}$ The blood-retinal barrier plays a major role in drug penetration into the vitreous (V) cavity. ${ }^{1,3}$ Hence, drug pharmacokinetics and pharmacodynamics should be considered when choosing an antibiotic drug regimen to treat infections such as endophthalmitis. Systemically administrated antibiotics such as aminoglycosides and vancomycin have not been shown to appreciably cross the blood-retinal barrier, and therefore unable to adequately penetrate into the $\mathrm{V}$ cavity. ${ }^{3-6}$ Antibiotic site penetration is also contingent on other factors such as site inflammation, lipid solubility of the drug, and drug bioavailability. Given these variables, it is imperative that clinicians take antibiotic choice, dose, and route of administration into consideration when treating bacterial endophthalmitis.

Historically, the mainstays of therapy against bacterial endophthalmitis include direct site administration techniques, including intravitreal injections of vancomycin, amikacin, and ceftazidime. ${ }^{7,8}$ A limitation to this type of drug administration includes their invasive nature. Alternatively, the systemic administration of these agents has also been studied but shown to have low to minimal penetration. ${ }^{3,9,10}$ This is of particular concern when treating drug-resistant organisms with high minimum inhibitory concentrations (MICs). The etiology of bacterial endophthalmitis is polymicrobial and may include gram-negative and gram-positive organisms, most notably methicillin-resistant Staphylococcus aureus (MRSA). ${ }^{11}$ Over the years, as new antibiotics with

\footnotetext{
${ }^{1}$ Department of Pharmacy Practice, University of the Sciences in Philadelphia, Philadelphia, Pennsylvania.

${ }^{2}$ College of Pharmacy, University of Illinois at Chicago, Chicago, Illinois.

${ }^{3}$ Department of Ophthalmology and Visual Sciences, University of Illinois at Chicago, Chicago, Illinois.

${ }^{4}$ Diseases of the Retina and Vitreous, University of Texas Health Sciences Center San Antonio, San Antonio, Texas.

${ }^{5}$ Department of Mathematics, Physics and Statistics, University of the Sciences in Philadelphia, Philadelphia, Pennsylvania.
} 
novel mechanisms of action and pharmacokinetic/pharmacodynamic properties have been introduced, recent literature describes the appreciable penetration of fluoroquinolones (gatifloxacin, moxifloxacin, levofloxacin, and ofloxacin) and linezolid, the only available oxazolidinone antibiotic, into the aqueous (AQ) and $\mathrm{V}$ cavities. ${ }^{12-21}$

With the growing concern in the increasing rate of ocular infections caused by MRSA and the report of the first case of postcataract endophthalmitis caused by vancomycinresistant enterococcus (VRE), it is important to include an agent with reliable activity against these pathogens in an empiric or treatment regimen. ${ }^{11,22}$ An alternative to fluoroquinolones should be considered for infections caused by MRSA as demonstrated by Asbell et al. and Miller et al. ${ }^{11,23}$ In the present study, the combination of oral levofloxacin and linezolid was studied because levofloxacin offers coverage against common gram-negative and gram-positive organisms; linezolid offers coverage against gram-positive ocular organisms, including MRSA and VRE.

The primary objective of this study was to measure and evaluate the time course of drug concentrations achieved in $\mathrm{S}, \mathrm{AQ}$, and $\mathrm{V}$ compartments after concomitant oral administration of linezolid and levofloxacin, before elective vitrectomy surgeries.

\section{Methods}

The study was approved by the University of Illinois at Chicago Institutional Review Board. Patients undergoing vitrectomy between April 2006 and April 2007 at the University of Illinois at Chicago who had not had a prior pars plana vitrectomy surgery in the study eye were randomly assigned to one of 4 groups. After informed consent, all subjects were given one oral dose of linezolid $600 \mathrm{mg}$ and levofloxacin $750 \mathrm{mg}$ each administered anywhere between $60 \mathrm{~min}$ and up to $12 \mathrm{~h}$ before the procedure: group $\mathrm{A}=1-3 \mathrm{~h}$; group $B=3-6 h$; group $C=6-9$; group $D=9-12 h$ before the procedure. Patients 18 years of age and older were included in the study. Exclusion criteria included any patient with a known hypersensitivity to either linezolid or levofloxacin; creatinine clearance $<30 \mathrm{~mL} / \mathrm{min}$ as defined by the Cockgroft-Gault method; pregnant or who were not on an effective means of contraception; history of pars plana vitrectomy surgery or intraocular silicone oil; hepatic dysfunction defined as baseline liver transaminases 3 times the upper limit of normal; or who have ingested any $\mathrm{Mg}^{+2}, \mathrm{Al}^{+3}, \mathrm{Fe}^{+3}, \mathrm{Zn}^{+2}$, or $\mathrm{Ca}^{+2}$ containing antacids and/or supplements within $2 \mathrm{~h}$ before or after administration of antibiotics. Data forms were designed to collect the following information: medical history, prescription history, linezolid and levofloxacin administration times, collection times of $A Q, V$, and serum (S) samples.

$A Q, V$, and $S$ samples were obtained before infusion of any irrigating solution to ensure undiluted samples. Approximately $0.1 \mathrm{~mL}$ of AQ fluid was aspirated by paracentesis with a 30-gauge needle. Approximately 0.2 to $0.3 \mathrm{~mL}$ of $\mathrm{V}$ fluid was obtained by a vitrector. All samples were collected at approximately the same time, although $\mathrm{S}$ samples were obtained just before any ocular manipulation. The interval between the last dose and the sample collection was noted. AQ and V samples were kept on ice and frozen at $-70^{\circ} \mathrm{C}$. The blood samples were centrifuged and the $S$ collected was frozen at $-70^{\circ} \mathrm{C}$. S concentrations of linezolid and levofloxacin were determined via a validated high-performance liquid chro- matography assay (HPLC) (Charles Peloquin, Director, Infectious Disease, Pharmacokinetics Laboratory, National Jewish Medical and Research Center, Denver, CO). Samples were measured using the ThermoFinnigan P4000 HPLC pump with a model AS1000 fixed-volume autosampler (Thermo Electron Corp), a model FL3000fluorescence detector, a Gateway Series e computer, and the ChromQuest HPLC data management system. The $\mathrm{S}$ standard curve for linezolid ranged from 0.5 to $30 \mu \mathrm{g} / \mathrm{mL}$. The absolute recovery time of linezolid from $\mathrm{S}$ was $95 \%$. The $\mathrm{S}$ standard curve for levofloxacin ranged from 0.20 to $15 \mu \mathrm{g} / \mathrm{mL}$. The absolute recovery time of levofloxacin from $\mathrm{S}$ was $90 \%$. The overall validation precision for levofloxacin and linezolid quality control samples was $0.76 \%$ to $4.83 \%$ and $1.04 \%$ to $4.39 \%$, respectively. Levofloxacin and linezolid concentrations in AQ and V fluids were calculated using the $S$ concentration curves. A one-sided $t$-test was performed to report any significant increases in drug concentrations between the groups. Descriptive statistical analysis (mean \pm standard deviations) were calculated using SPSS version 9.0 package.

\section{Results}

The average age of patients was 53 years. Baseline characteristics are presented in Table 1 . The mean $A Q, V$, and $S$ levels achieved after a single dose of levofloxacin $750 \mathrm{mg}$ and linezolid $600 \mathrm{mg}$ are shown in Table 2. Mean AQ concentrations of linezolid and levofloxacin peaked at an average time of $118 \mathrm{~min}$ after administration, $4.98 \pm 2.39$ and $3.54 \pm 2.94 \mu \mathrm{g} /$ $\mathrm{mL}$, respectively. Corresponding linezolid and levofloxacin $\mathrm{S}$ levels were $11.56 \pm 2.89$ and $9.6 \pm 3.37 \mu \mathrm{g} / \mathrm{mL}$, respectively. Mean V concentrations of linezolid and levofloxacin peaked at an average time of 428 and $602 \mathrm{~min}$ after administration, $3.74 \pm 3.08$ and $2.83 \pm 0.80 \mu \mathrm{g} / \mathrm{mL}$, respectively. Corresponding linezolid and levofloxacin $S$ levels were $6.49 \pm 1.69$ and $5.53 \pm 0.42 \mu \mathrm{g} / \mathrm{mL}$, respectively (Table 2 ).

Concentration versus time profiles for both levofloxacin and linezolid are depicted in Figs. 1 and 2. In the AQ compartment, a significant increase was seen in linezolid concentrations between groups A (average $=118 \mathrm{~min}$ ) and $\mathrm{B}$ (average $=237 \mathrm{~min})(P=0.015)$ [Fig. 3]. An increase was also observed in levofloxacin concentrations between groups A and $\mathrm{B}$; however, this did not reach statistical significance $(P=0.055)$. In the $\mathrm{V}$ compartment, a significant increase was observed in levofloxacin concentrations between groups A (average $=118 \mathrm{~min})$ and $\mathrm{D}($ average $=602 \mathrm{~min})(P=0.021)$ [Fig. 4].

Both linezolid and levofloxacin achieved concentrations at or above minimum inhibitory concentration for $90 \%\left(\mathrm{MIC}_{90}\right)$ of isolates $(1-2 \mu \mathrm{g} / \mathrm{mL})$ of common ocular pathogens in $\mathrm{S}, \mathrm{AQ}$, and $\mathrm{V}$ compartments $2 \mathrm{~h}$ after administration (Figs. 3-5). The in vitro susceptibility of levofloxacin and linezolid are listed in Table 3. Both linezolid and levofloxacin were able to achieve

Table 1. Patient Baseline Characteristics

\begin{tabular}{lcccc}
\hline Group & $\begin{array}{c}\text { No. of } \\
\text { eyes (N) }\end{array}$ & $\begin{array}{c}\text { Gender } \\
(M / F)\end{array}$ & $\begin{array}{c}\text { Mean age } \\
\text { (range), years }\end{array}$ & $\begin{array}{c}\text { No. of diabetic } \\
\text { patients (n) }\end{array}$ \\
\hline Group A & 5 & 1F; 4M & $46.8(28-64)$ & 3 \\
Group B & 5 & 4 F; 1 M & $51.6(29-64)$ & 4 \\
Group C & 3 & 2F; 1M & $57.7(53-66)$ & 2 \\
Group D & 3 & 2F; 1M & $56.3(45-67)$ & 2 \\
\hline
\end{tabular}


Table 2. Mean \pm Standard Deviation Aqueous, Vitreous, and Serum Concentrations OF LiNEZOLID 600 MG AND LEVOFLOXACIN 750 MG

\begin{tabular}{|c|c|c|c|c|c|c|}
\hline \multirow{3}{*}{$\begin{array}{c}\text { Time of administration before } \\
\text { procedure (average time) } \\
{[\mathrm{N}=\text { number of eyes }]}\end{array}$} & \multicolumn{6}{|c|}{ Mean concentrations $\pm S D(\mu g / m L)$} \\
\hline & \multicolumn{3}{|c|}{ Linezolid $600 \mathrm{mg}$} & \multicolumn{3}{|c|}{ Levofloxacin $750 \mathrm{mg}$} \\
\hline & $A Q$ & $V$ & $S$ & $A Q$ & $V$ & $S$ \\
\hline Overall: $1-12 \mathrm{~h}(N=16)$ & $3.32 \pm 2.06$ & $2.98 \pm 1.87$ & $7.91 \pm 3.94$ & $2.19 \pm 1.92$ & $1.95 \pm 1.27$ & $7.38 \pm 3.47$ \\
\hline Group A: $1-3 \mathrm{~h}(119 \mathrm{~min})[N=5]$ & $1.9 \pm 1.09$ & $1.78 \pm 1.83$ & $7.14 \pm 4.37$ & $1.14 \pm 0.52$ & $1.08 \pm 0.99$ & $5.84 \pm 3.91$ \\
\hline Group B: $3-6 \mathrm{~h}(237 \mathrm{~min})[N=5]$ & $4.98 \pm 2.39$ & $3.29 \pm 1.16$ & $11.56 \pm 2.89$ & $3.54 \pm 2.94$ & $1.92 \pm 0.84$ & $9.6 \pm 3.37$ \\
\hline Group C: $6-9 \mathrm{~h}(428 \mathrm{~min})[N=3]$ & $3.39 \pm 1.69$ & $3.74 \pm 3.08$ & $6.49 \pm 1.69$ & $1.75 \pm 0.36$ & $2.61 \pm 2.08$ & $8.07 \pm 3.58$ \\
\hline Group D: $9-12 \mathrm{~h}(602 \mathrm{~min})[N=3]$ & $2.82 \pm 1.69$ & $3.69 \pm 1.41$ & $4.53 \pm 1.98$ & $2.11 \pm 1.39$ & $2.83 \pm 0.80$ & $5.53 \pm 0.42$ \\
\hline
\end{tabular}

$\mathrm{AQ}$, aqueous; $\mathrm{V}$, vitreous; $\mathrm{S}$, serum; $\mathrm{SD}$, standard deviation.

significantly higher $(P<0.05) \mathrm{S}$ concentrations above the $\mathrm{MIC}_{90} \leq 2 \mu \mathrm{g} / \mathrm{mL}$ in all groups with the exception of linezolid in group D. The average time to sampling in group $\mathrm{D}$ was 602 min after drug administration. In both AQ and V compartments, only linezolid achieved concentrations significantly higher than that of organisms with an $\mathrm{MIC}_{90} \leq 2 \mu \mathrm{g} / \mathrm{mL}$ in group $\mathrm{B}, \sim 237 \mathrm{~min}$ after drug administration. For organisms with an $\mathrm{MIC}_{90} \leq 1 \mu \mathrm{g} / \mathrm{mL}$, in the $\mathrm{AQ}$ compartment, levofloxacin concentrations in group $\mathrm{C}$ achieved significantly higher concentrations $(P<0.05)$. The average time to sampling was $428 \mathrm{~min}$ after drug administration. In the $\mathrm{V}$ compartment, levofloxacin concentrations achieved above the $\mathrm{MIC}_{90} \leq 1 \mu \mathrm{g} / \mathrm{mL}$ in groups B and D reached statistical significance. Linezolid achieved significant concentrations above the $\mathrm{MIC}_{90} \leq 1 \mu \mathrm{g} / \mathrm{mL}$ only in group $\mathrm{D}(P<0.05)$.

The time course of drug concentrations achieved in each compartment was evaluated. Table 2 describes the achieved mean concentrations of linezolid and levofloxacin into respective compartments. Individual patient data is not shown. Samples collected after linezolid administration achieved AQ and $\mathrm{V}$ concentrations of $>2 \mu \mathrm{g} / \mathrm{mL}$ within the first $3 \mathrm{~h}$ in 1 of 5 eyes (20\%) and within $6 \mathrm{~h}$ in 4 out of 5 eyes (80\%), respectively. Concentrations of levofloxacin did not achieve appreciable levels above the $\mathrm{MIC}_{90}(2 \mu \mathrm{g} / \mathrm{mL})$ of common ocular pathogens in the $\mathrm{AQ}$ or $\mathrm{V}$ compartments within the first $3 \mathrm{~h}$ after administration. In samples collected 3-9 hours (median 6 hours) after levofloxacin administration, 5 out of $8(63 \%)$ and 4 out of $8(50 \%)$ achieved concentrations $\geq 2 \mu \mathrm{g} / \mathrm{mL}$. Mean concentrations of $>1 \mu \mathrm{g} / \mathrm{mL}$ for both linezolid and levofloxacin were maintained for up to $12 \mathrm{~h}$ after drug administration in both AQ and $\mathrm{V}$ compartments. The maximum corresponding $\mathrm{S}$ levels of linezolid and levofloxacin were achieved in the first $6 \mathrm{~h}$ after administration.

For a planned vitrectomy, to ensure adequate $\mathrm{V}$ concentrations above common organisms with $\mathrm{MIC} \leq 2 \mu \mathrm{g} / \mathrm{mL}$, it appears that the optimal time to administer linezolid and levofloxacin would be at least $428 \mathrm{~min}$ or $6-7 \mathrm{~h}$ before the surgery. The corresponding $S$ levels for both agents would also be well above the MIC for common gram-positive and gram-negative organisms (Table 2).

Both linezolid and levofloxacin were well tolerated in all patients, with no drug-related adverse effects reported.
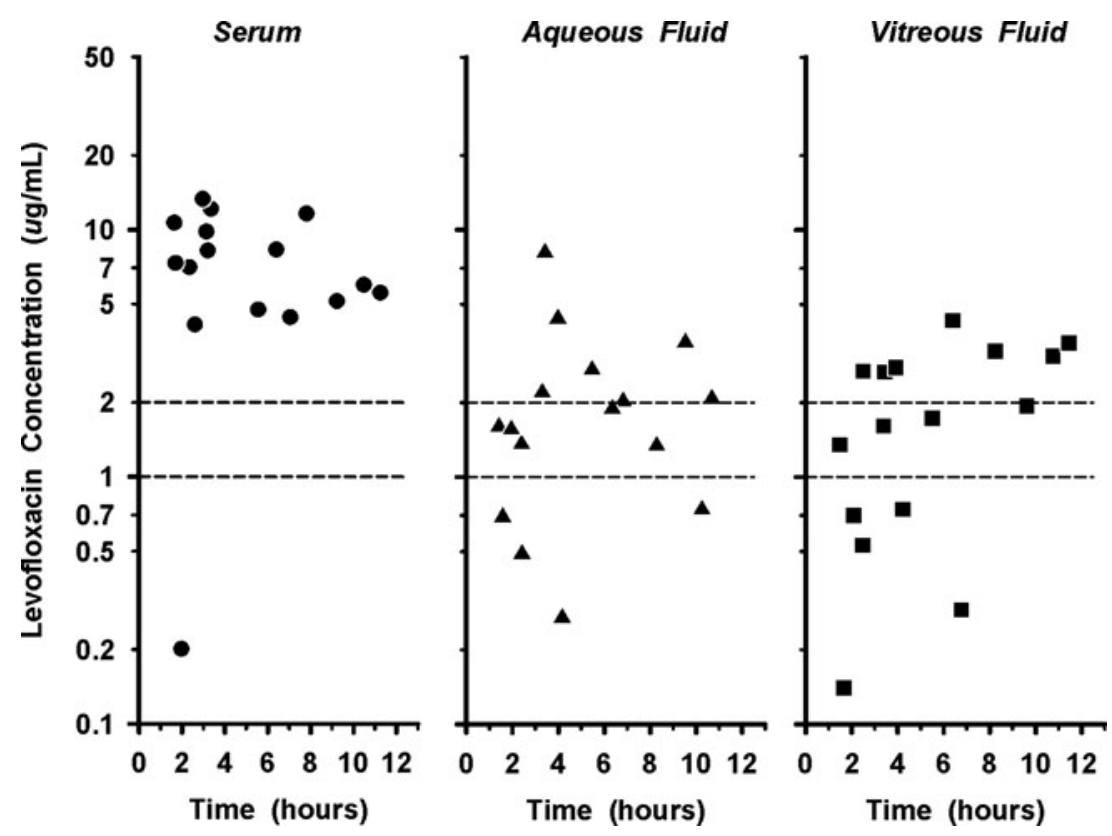

FIG. 1. Concentration versus time profile for levofloxacin in plasma, aqueous humor, and vitreous humor. (-) Representative of MIC values of 1.0. (-) Representative of MIC values of $2.0 \mu \mathrm{g} / \mathrm{mL}$. The y-axis is in the log scale. MIC, minimum inhibitory concentration. 

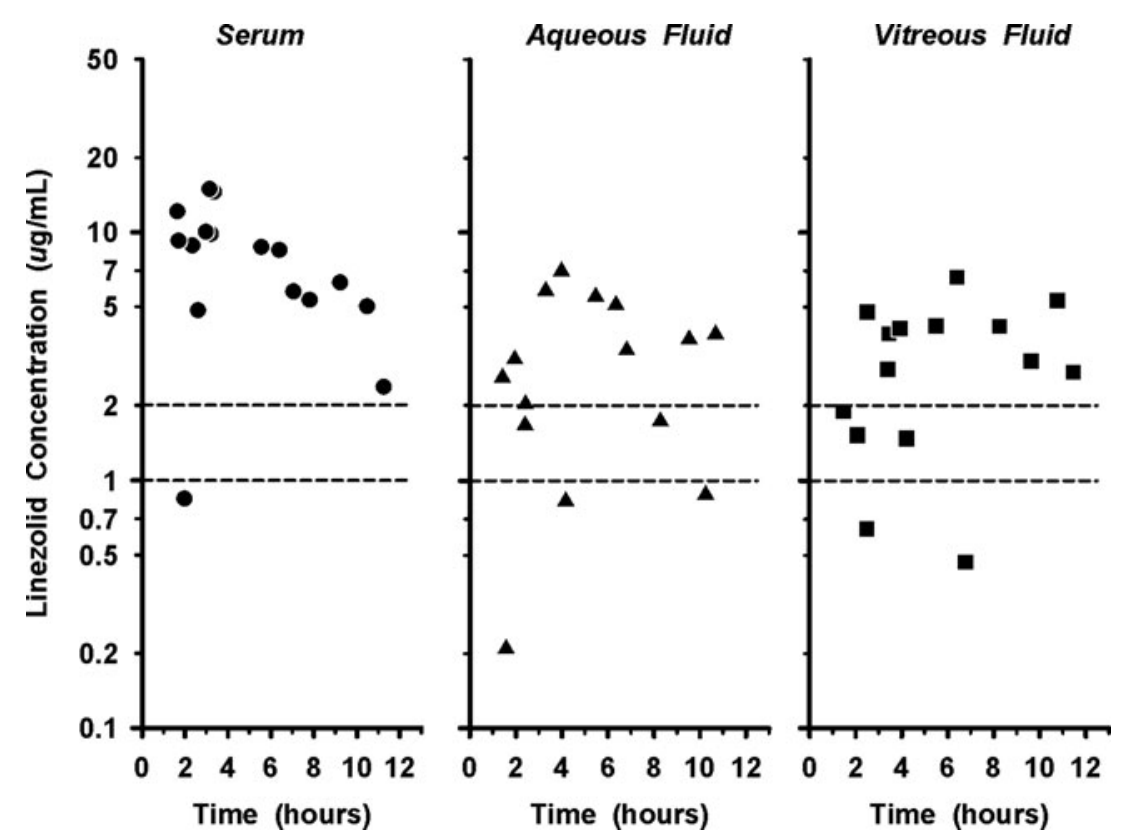

FIG. 2. Concentration versus time profile for linezolid in plasma, aqueous humor, and vitreous humor. (-) Representative of MIC values of 1.0. (-) Representative of MIC values of $2.0 \mu \mathrm{g} / \mathrm{mL}$. The y-axis is in the $\log$ scale.

\section{Discussion}

The combination of oral levofloxacin and linezolid has not been studied until this investigation.

Linezolid and levofloxacin were chosen because of their spectrum of activity and oral bioavailability. Organisms isolated from the eyelid margin and preocular tear film often determines the etiology of postoperative endophthalmitis. These include gram-positive organisms: Staphylococcus epi-

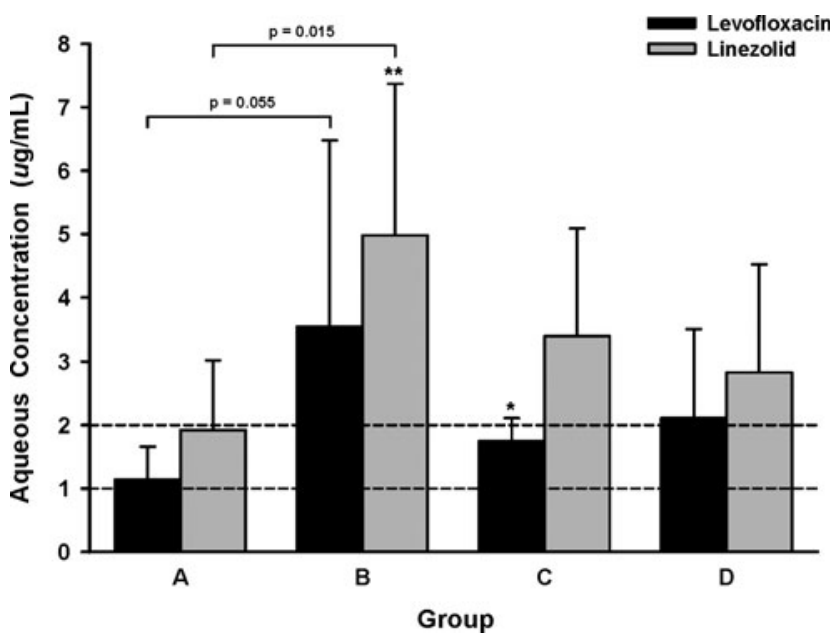

FIG. 3. Mean concentrations \pm standard deviation (SD) of levofloxacin and linezolid achieved in serum for each group. Error bars represent the SD. (-) Representative of MIC value of $1 \mu \mathrm{g} / \mathrm{mL}$. (-) Representative of MIC value of $2 \mu \mathrm{g} / \mathrm{mL}$. *An average concentration significantly above an MIC value of $1 \mu \mathrm{g} / \mathrm{mL}\left(\alpha=0.05\right.$, one-sided $t$-test). ${ }^{* *}$ An average concentration significantly above an MIC value of $2 \mu \mathrm{g} / \mathrm{mL} .(\alpha=0.05$, one-sided $t$-test). $P$ representative of $P$ value (one-sided $t$-test) to verify a significant increase in concentration. Group A: $0-3 \mathrm{~h}$; group B: 3-6h; group C: 6-9h; group D: 9-12 h. dermidis accounting for $70 \%$ of cases, followed by S. aureus, streptococci, enterococci, and Propionibacterium acnes. ${ }^{3,6}$ Posttraumatic endophthalmitis has been reported to occur at an incidence as high as $17 \% .^{3}$ The etiology can be polymicrobial and include staphylococci, Bacillus cereus, and gram-negative organisms. With the recent concern over fluoroquinolone resistance in staphylococcal infections, it is not recommended to use fluoroquinolone monotherapy to treat invasive infections such as endophthalmitis. ${ }^{23}$ Of notable interest are the recent

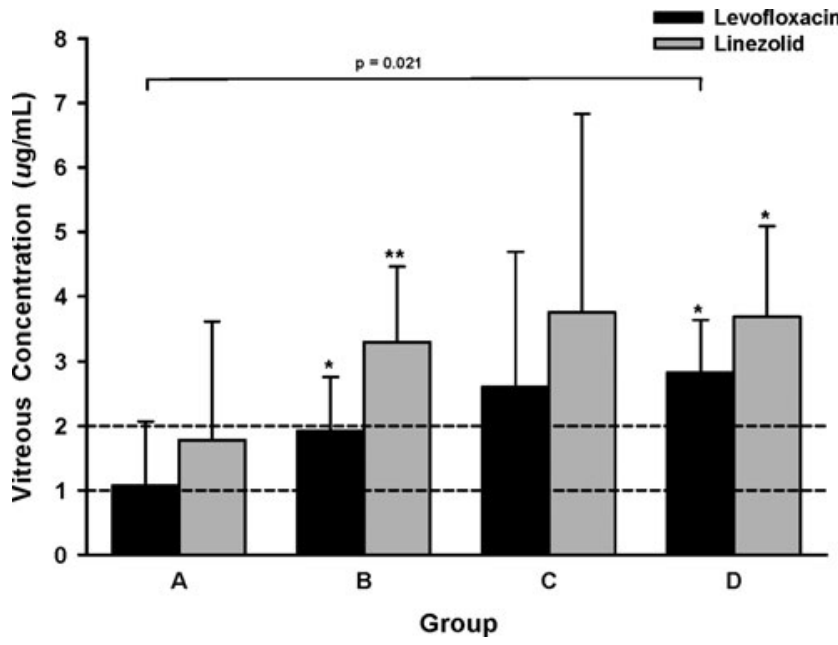

FIG. 4. Mean concentrations $\pm S D$ of levofloxacin and linezolid achieved in aqueous fluid for each group. Error bars represent the SD. (-) Representative of MIC value of $1 \mu \mathrm{g} /$ $\mathrm{mL}$. (-) Representative of MIC value of $2 \mu \mathrm{g} / \mathrm{mL}$. *An average concentration significantly above an MIC value of $1 \mu \mathrm{g} /$ $\mathrm{mL}\left(\alpha=0.05\right.$, one-sided $t$-test). ${ }^{* *} \mathrm{An}$ average concentration significantly above an MIC value of $2 \mu \mathrm{g} / \mathrm{mL}$. $(\alpha=0.05$, onesided $t$-test). $P$ representative of $P$ value (one-sided $t$-test) to verify a significant increase in concentration. Group A: $0-3 \mathrm{~h}$; group B: 3-6h; group C: 6-9h; group D: 9-12 h. 


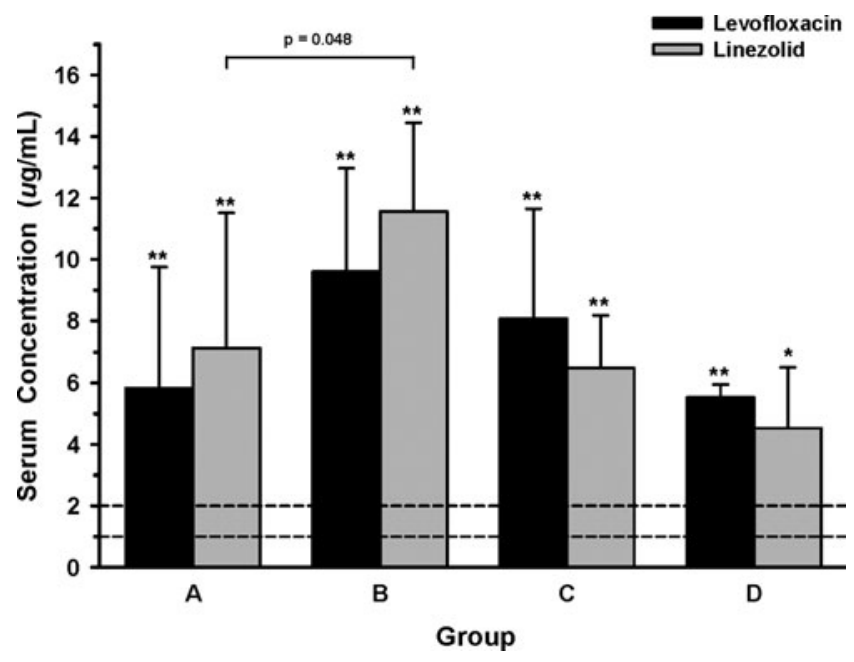

FIG. 5. Mean concentrations $\pm S D$ of levofloxacin and linezolid achieved in vitreous fluid for each group. Error bars represent the SD. (-) Representative of MIC value of $1 \mu \mathrm{g} /$ mL. (-) Representative of MIC value of $2 \mu \mathrm{g} / \mathrm{mL}$. *An average concentration significantly above an MIC value of $1 \mu \mathrm{g} /$ $\mathrm{mL}\left(\alpha=0.05\right.$, one-sided $t$-test). ${ }^{* *}$ An average concentration significantly above an MIC value of $2 \mu \mathrm{g} / \mathrm{mL}$. $(\alpha=0.05$, onesided $t$-test). $P$ representative of $P$ value (one-sided $t$-test) to verify a significant increase in concentration. Group A: 0-3h; group B: 3-6h; group C: 6-9 h; group D: 9-12 h.

ocular TRUST data on ophthalmic pathogens that reports $\mathrm{MIC}_{90}$ of 16 for MSSA and MRSA to levofloxacin (Table 3). ${ }^{11}$ A recent editorial by Jones $D$ calls attention to the emergence of antibiotic resistance, including infections caused by MRSA and VRE. ${ }^{24}$ In addition to topical applications, the editorial describes the need for considering newer systemic agents, such as linezolid, daptomycin, and tigecycline, as potential treatment options in light of the growing concern for infections caused by MRSA and VRE. Sharma $S$ et al. reported the first case of postcataract vancomycin-resistant Enterococcus faecium endophthalmitis treated successfully with intravenous and oral linezolid. ${ }^{22}$ Further, Bains et al. reported the successful treatment of E. faecium endophthalmitis after penetrating keratoplasty with topical, oral, and intravenous linezolid. ${ }^{25}$ As resistance to fluoroquinolones increase and the incidence of infections caused by MRSA and VRE is on the rise, combination oral therapy with linezolid becomes an appropriate treatment option.

Our study demonstrated that oral levofloxacin and linezolid achieved the mimimum inhibitory concentrations in both $\mathrm{AQ}$ and $\mathrm{V}$ compartments against common ocular pathogens, including VRE, MRSA, and streptococcal species. Linezolid is available both intravenously and orally as $600 \mathrm{mg}$ given twice a day. ${ }^{26}$ Linezolid concentrations above the $\mathrm{MIC}_{90}$ of isolates were reached in the V fluid against S. aureus, S. epidermidis, Streptococcus pneumoniae, B. cereus, and P. acnes. Levofloxacin is available both intravenously and orally as 250, 500 , and $750 \mathrm{mg}$ once daily dosing. ${ }^{27}$ Although the penetration of oral levofloxacin has been studied by previous investigators, this is the first study to use the newer higher dosage form of $750 \mathrm{mg}$ levofloxacin. ${ }^{13,15}$ Because levofloxacin exhibits concentration-dependent killing, the study investigators believed that using the higher dosage form would ensure greater levels into the $\mathrm{V}$ cavity. Fiscella et al. reported $\mathrm{V}$ concentrations after oral administration of a single $500 \mathrm{mg}$ dose of levofloxacin to be $0.59 \pm 0.30 \mu \mathrm{g} / \mathrm{mL}$ after $120 \mathrm{~min}$
Table 3. In Vitro Activity Minimum Inhibitory CONCENTRATION FOR 90\% OF LEVOFLOXACIN AND LiNeZOlid FOR SElected ORganisms

\begin{tabular}{lcc}
\hline Organism & $\begin{array}{c}\text { Levofloxacin } \\
(\mu g / m L)\end{array}$ & $\begin{array}{c}\text { Linezolid } \\
(\mu g / m L)\end{array}$ \\
\hline $\begin{array}{l}\text { Gram positive } \\
\text { Bacillus cereus }\end{array}$ & 2 & 1 \\
$\begin{array}{l}\text { Streptococcus species } \\
\quad \text { Streptococcus pneumoniae }\end{array}$ & 1 & 1 \\
$\quad$ Viridans group streptococci & 2 & 1 \\
Staphylococcus species & 16 & 2 \\
$\quad$ Staphylococcus aureus (MSSA) & 16 & $2-4$ \\
$\quad$ Staphylococcus aureus (MRSA) & - & 1 \\
$\quad$ Staphylococcus epidermidis & - & $1-4$ \\
Enterococcus species (VS) & -4 \\
Enterococcus species (VR) & & \\
Gram negative & 4 & - \\
Escherichia coli & 2 & - \\
Klebsiella pneumoniae & 1 & 0.5 \\
Serratia marcescens & & \\
Anaerobes & - & \\
\hline
\end{tabular}

Adapted from references 11 and 31-35.

Levofloxacin: Clinical and Laboratory Standards Institute (CLSI) breakpoints for Enterococcus faecalis, methicillin-sensitive $S$. aureus are susceptible at $<2 \mu \mathrm{g} / \mathrm{mL}$, intermediate at $4 \mu \mathrm{g} / \mathrm{mL}$, and resistant at $>8 \mu \mathrm{g} / \mathrm{mL}$.

CLSI breakpoints for S. pneumoniae are susceptible at $<2 \mu \mathrm{g} / \mathrm{mL}$. Linezolid: CLSI breakpoints for Enterococcus spp. are susceptible at $<2 \mu \mathrm{g} / \mathrm{mL}$, intermediate at $4 \mu \mathrm{g} / \mathrm{mL}$, and resistant at $>8 \mu \mathrm{g} / \mathrm{mL}$. CLSI breakpoints for Staphylococcus spp. and S. pneumoniae are susceptible at $<4 \mu \mathrm{g} / \mathrm{mL}$ and $<2 \mu \mathrm{g} / \mathrm{mL}$, respectively.

MSSA, methicillin-sensitive Staphylococcus aureus; MRSA, methicillin-resistant Staphylococcus aureus; VS, vancomycin sensitive; VR, vancomycin resistant.

after administration. ${ }^{13}$ In the present study, a single oral dose of levofloxacin $750 \mathrm{mg}$ achieved a V concentration of $1.08 \pm$ $0.99 \mu \mathrm{g} / \mathrm{mL}$ at the first sampling time $(119 \mathrm{~min})$. Concentrations continued to increase at each sampling period to an overall higher average concentration of $2.83 \pm 0.80 \mu \mathrm{g} / \mathrm{mL}$ after $\sim 602 \mathrm{~min}$ after administration.

The AQ and V concentrations that were achieved after oral administration of linezolid and levofloxacin in our study were comparable to that of previous studies (Table 4). Fiscella et al. described the appreciable penetration of a single $600 \mathrm{mg}$ linezolid dose into $\mathrm{V}$ fluid achieving concentrations $2 \mathrm{~h}$ postdose above the $\mathrm{MIC}_{90}$ of selected gram-positive bacteria (S. aureus, S. epidermidis, S. pneumonia, B. cereus, and P. acnes). ${ }^{14}$ The same investigators studied the AQ and $\mathrm{V}$ penetration of two- $500 \mathrm{mg}$ tablets of oral levofloxacin and determined the mean concentrations achieved in the AQ and $\mathrm{V}$ humors to be above the $\mathrm{MIC}_{90}$ of common ocular pathogens, $1.98 \pm 1.02$ and $2.48 \pm 0.68 \mu \mathrm{g} / \mathrm{mL}$, respectively. ${ }^{13}$ Lott et al. reported the mean concentration achieved in the $\mathrm{V}$ cavity after 5 consecutive daily doses of moxifloxacin was $1.200 \pm 0.645 \mu \mathrm{g} / \mathrm{mL}^{16}$ Sakamoto et al. reported a $400 \mathrm{mg}$ dose of levofloxacin before a vitrectomy achieved appreciable concentrations into the AQ and V humors $(1.28 \pm 0.44$ and $1.45 \pm 0.45 \mu \mathrm{g} / \mathrm{mL}$, respectively). ${ }^{15}$

Although the use of intravitreal antibiotics have increased over the years, visual outcomes still remain poor. ${ }^{28,29} \mathrm{Ng}$ et al. and Coyler et al. have suggested that administration of oral antibiotics (fluoroquinolones) in conjunction with topical 


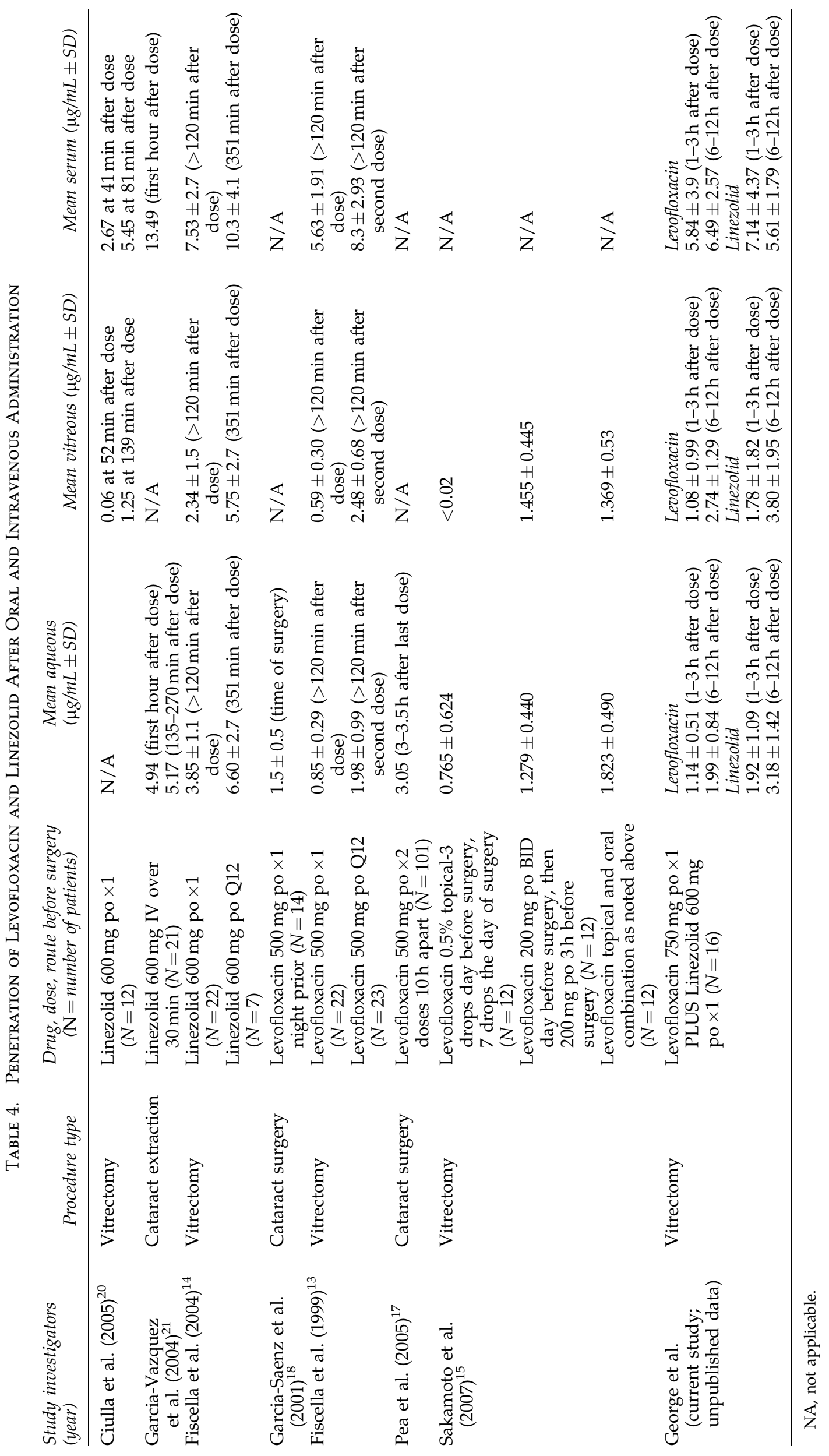


antibiotics may be associated with better visual outcomes for endophthalmitis (postcataract, trauma, etc). ${ }^{8,30}$ Cantor and colleagues report superior AQ levels achieved after a combination of topical and oral levofloxacin when compared with a topical and oral combination ciprofloxacin in bleb associated infections. ${ }^{19}$ When compared with levofloxacin $500 \mathrm{mg}$, the larger dose of $750 \mathrm{mg}$ used in the present study resulted in higher levels in the AQ and V compartments. Perhaps combining oral levofloxacin $750 \mathrm{mg}$ with topical levofloxacin $1.5 \%$ may provide a significant increase in anterior chamber levels.

The interest from a pharmacokinetic standpoint is the concentration versus time profile of these combined antibiotics. Linezolid $600 \mathrm{mg}$ and levofloxacin $750 \mathrm{mg}$ orally provide for inhibitory concentrations in the $\mathrm{V}$ fluid within $\sim 3 \mathrm{~h}$. This is of critical importance because the combination of these 2 antibiotics provides a spectrum of coverage against many ocular pathogens in endophthalmitis within $3 \mathrm{~h}$ and in the majority of cases within 3 to $6 \mathrm{~h}$.

Both linezolid and levofloxacin are 100\% orally bioavailable and hence are attractive options because of their ease of administration. Oral levofloxacin and linezolid could supplement current treatment strategies or provide an immediate and convenient treatment option in high-risk patients. These high-risk patients include those who live in rural areas where a general cataract surgeon can provide immediate treatment while awaiting a retina specialist.

Linezolid and levofloxacin are well-tolerated agents. ${ }^{36}$ Rare but serious side effects with linezolid include thrombocytopenia. This has been reported in $<10 \%$ of patients and is most likely to occur after the first 2 weeks of therapy. Adverse effects reported with levofloxacin include torsades de pointes and tendon inflammation and/or rupture $(<1 \%)$. These side effects are more likely to occur in patients over the age of 60 years. Concomitant administration with cation/anion containing agents is reported to decrease the achievable $S$ concentrations of levofloxacin. Therefore, antacids and other calcium or magnesium containing salts should be separated by $2 \mathrm{~h}$ from oral levofloxacin administration. There are minimal drug interactions that are reported with linezolid. Linezolid possesses weak mono-amine oxidase inhibitor properties; therefore, administering this agent with other mono-amine oxidase inhibitors or serotonergic agents may increase the risk of serotonin syndrome. Although the reported incidence is low $(<1 \%)$, patients should still be closely monitored for signs and symptoms of serotonin syndrome. Patients with a history of uncontrolled hypertension should also be closely monitored for signs and symptoms of increased blood pressure.

In summary, concomitant administration of oral levofloxacin and linezolid achieves therapeutic concentrations in the $\mathrm{AQ}$ and $\mathrm{V}$ fluids. In addition, the combination of these agents provides broad-spectrum antimicrobial coverage against common ocular pathogens. Because of their excellent pharmacokinetic profile, bioavailability, minimal side effects, and spectrum of activity, this combination offers an attractive option in the adjunctive therapy for endophthalmitis.

\section{Author Disclosure Statement}

Keith Rodvold-Johnson and Johnson/Ortho-McNeil Pharmaceuticals: Consultant/Advisor and Lecture Fees; Pfizer: Consultant/Advisor and Lecture Fees.

Lawrence J. Ulanski-Allergan Inc.: Consultant fee.
Jomy M. George--Pfizer: Consultant Fees.

Richard Fiscella, Lawrence Ulanski, Michael Blair, Norman Blair, and Laura Pontiggia-no competing financial interests exist.

\section{References}

1. Durand, M.L. Endophthalmitis. In: Mandell, G.L., Bennett, J.E., Dolin, R., eds. Principles and Practice of Infectious Diseases. Pennsylvania: Elseiver, Inc.; 2005; p. 1406-1411.

2. Drusano, G., Liu, E., Perkins, R., et al. Determination of robust ocular pharmacokinetic parameters in serum and vitreous humor of albino rabbits following systemic administration of ciprofloxacin from sparse data sets by using it2s, a population pharmacokinetic modeling program. Antimicrob. Agents Chemother. 39:1683-1687, 1995.

3. Callegan, M., Gilmore, M.S., Gregory, M., et al. Bacterial endophthalmitis: therapeutic challenges and host-pathogen interactions. Prog. Retin. Eye Res. 26:189-203, 2007.

4. Rubinstein, E., Goldfarb, J., Keren, G., Blumenthal, M., and Treister, G. The penetration of gentamicin into thevitreous humor in man. Invest. Ophthalmol. Vis. Sci. 24:637-639, 1983.

5. Ferencz, J.R., Assia, E.I., Diamantstein, L., and Rubinstein, E. Vancomycin concentration in the vitreous after intravenous and intravitreal administration for postoperative endophthalmitis. Arch. Ophthalmol. 117:1023-1027, 1999.

6. Endophthalmitis Vitrectomy Study Group. Results of the Endophthalmitis Vitrectomy Study: a randomized trial of immediate vitrectomy and intravenous antibiotics for the treatment of postoperative bacterial endophthalmitis. Arch. Ophthalmol. 113:1479-1496, 1995.

7. Ciulla, T., Starr, M., and Masket, S. Bacterial endophthalmitis prophylaxis for cataract surgery. Opthalmology 109 : 13-26, 2002.

8. $\mathrm{Ng}$, J.Q., Morlet, N., Pearman, J.W., et al. Management and outcomes of postoperative endophthalmitis since the endophthalmitis vitrectomy study. Opthalmology 112:1199-1206, 2005.

9. Doft, B.H. Treatment of postcataract endophthalmitis: summary of the results from the Endophtahlmitis Vitrectomy Study. Arch. Ophthalmol. 126:554-556, 2008.

10. Flynn, H.W., and Scott, I.U. Legacy of the Endophtahlmitis Vitrectomy Study. Arch. Ophthalmol. 126:559-561, 2008.

11. Asbell, P.A., Colby, K.A., Deng, S., et al. Ocular TRUST: nationwide antimicrobial susceptibility patterns in ocular isolates. Am. J. Ophthamol. 145:951-958, 2008.

12. Hariprasad, S.M., Guarav, K.S., Meiler, W.F., et al. Vitreous and aqueous penetration of orally administered moxifloxacin in humans. Arch. Opthalmol. 124:178-182, 2006.

13. Fiscella, R.G., Nguyen, T.K.P., Cwik, M.J., et al. Aqueous and vitreous penetration of levofloxacin after oral administration. Opthalmology 106:2286-2290, 1999.

14. Fiscella, R.G., Lai, W.W., Buerk, B., et al. Aqueous and vitreous penetration of linezolid (Zyvox ${ }^{\circledR}$ ) after oral administration. Opthalmology 111:1191-1195, 2004.

15. Sakamoto, H., Sakamoto, M., Hata, Y., Kubota, T., and Ishibashi, T. Aqueous and vitreous penetration of levofloxacin after topical and/or oral administration. Eur. J. Ophthalmol. 17:372-376, 2007.

16. Lott, M.N., Fuller, J.J., Hancock, H.A., et al. Vitreal penetration of oral moxifloxacin in humans. Retina 28:473-476, 2008.

17. Pea, F., Ferrari, E., Pavan, F., et al. Levofloxacin disposition over time in aqueous humor of patients undergoing cataract surgery. Antimicrob. Agents Chemother. 49:2554-2557, 2005. 
18. Garcia-Saenz, M.C., Aria-Puente, A., Fresnadillo-Martinez, M.J., and Carrasco-Font, C. Human aqueous humor levels of oral ciprofloxacin, levofloxacin, and moxifloxacin. J. Cataract Refract. Surg. 27:1969-1974, 2001.

19. Cantor, L.B., WuDunn, D., Yung, C.W., et al. Ocular penetration of levofloxacin, ofloxacin, ciprofloxacin in eyes with functioning filtering blebs: investigator masked, randomized clinical trial. Br. J. Ophthalmol. 92:345-347, 2008.

20. Ciulla, T.A., Comer, M., Peloquin, C., and Wheeler, J. Human vitreous distribution of oral linezolid after a single dose. Retina 25:619-624, 2005.

21. Garcia-Vazquez, E., Mensa, J., Lopez, Y., et al. Penetration of linezolid into the anterior chamber (aqueous humor) of the human eye after intravenous administration. Antimicrob. Agents Chemother. 48:670-672, 2004.

22. Sharma, S., Desai, R., Pass, A., and Saffra, N. Vancomycin resistant enterococcal endophthalmitis. Arch. Ophthalmol. 128:794-795, 2010.

23. Miller, D., Flynn, P.M., Scott, I.U., Alfonso, E.C., and Flynn, H.W., Jr. In vitro fluoroquinolone resistance in staphylococcal endophthalmitis isolates. Arch. Ophthalmol. 124:479-483, 2006.

24. Jones, D. Emerging vancomycin resistance: what are we waiting for? Arch. Ophthalmol. 128:789-791, 2010.

25. Bains, H.S., Weinberg, D.V., Feder, R.S., and Noskin, G.A. Postoperative vancomycin resistant Enterococcus faecium endophthalmitis. Arch. Ophthalmol. 125:1292-1293, 2007.

26. Zyvox prescribing information 2010. Pharmacia and Upjohn Company- Division of Pfizer Inc.

27. Levaquin prescribing information 2009. Ortho-McNeilJanssen Pharmaceuticals, Inc.

28. Deramo, V.A., Lai, J.C., Winokur, J., Luchs, J., and Udell, I.J. Visual outcome and bacterial sensitivity after methicillinresistant Staphylococcus aureus associated acute endophthalmitis. Am. J. Ophthalmol. 145:413-417, 2008.

29. Lalwani, G.A., Flynn, H.W., Scott, I.V., et al. Acute onset endophthalmitis after corneal cataract surgery (1996-2005). Ophthalmology 115:473-476, 2008.
30. Coyler, M.H., Weber, E.D., Weichel, E.D., et al. Delayed intraocular foreign body removal without endophthalmitis during operation Iraqi freedom and enduring freedom. Ophthalmology 114:1439-1447, 2007.

31. Jones, R.N., Fritsche, T.R., Sader, H.S., and Ross, J.E. Zyvox annual appraisal of potency and spectrum program results for 2006: an activity and spectrum analysis of linezolid using clinical isolates from 16 countries. Diagn. Microbiol. Infect. Dis. 59:199-209, 2007.

32. Jones, R.N., Sader, H.S., and Beach, M.L. Contemporary in vitro spectrum of activity summary for antimicrobial agents tested against 18569 strains non-fermentative Gramnegative bacilli isolated in the SENTRY Antimicrobial Surveillance Program (1997-2001). Int. J. Antimicrob. Agents 22:551-556, 2003.

33. Lanzafone, A., Bonfiglio, G., Santini, L., and Mattina, R. In vitro activity of levofloxacin against recent Gram-negative nosocomial pathogens. Chemotherapy 51:44-50, 2005.

34. Rolston, K.V.I., Ho, D.H., LeBlanc, B., et al. In vitro activity of trovafloxacin against clinical bacterial isolates from patients with cancer. J. Antimicrob. Chemother. 39 (Suppl B):15-22, 1997.

35. Diekema, D.J., and Jones, R.N. Oxazolidinone antibiotics. Lancet 358:1975-1982, 2001.

36. Micromedex healthcare series online. Available at www .micromedex.com. University of the Sciences in Philadelphia online library www.usp.edu, accessed May 18, 2010.

Received: February 8, 2010

Accepted: August 30, 2010

Address correspondence to: Jomy M. George, PharmD, BCPS Department of Pharmacy Practice University of the Sciences in Philadelphia GH $108 \mathrm{~K}$ Philadelphia, PA 19104 E-mail: j.george@usp.edu 
Copyright of Journal of Ocular Pharmacology \& Therapeutics is the property of Mary Ann Liebert, Inc. and its content may not be copied or emailed to multiple sites or posted to a listserv without the copyright holder's express written permission. However, users may print, download, or email articles for individual use. 